\title{
Formação pedagógica e desenvolvimento profissional no ensino superior: perspetivas de docentes
}

\author{
Marta Mateus de Almeida
}

\section{RESUMO}

O texto apresenta os resultados de um estudo em que se procurou perceber que práticas de desenvolvimento profissional são reconhecidas por docentes do ensino superior, em particular para a dimensão do ensino. Visou-se ainda compreender como esses atores percecionam a formação pedagógica. Inscrevendo-se em uma abordagem mista, com recurso à técnica de entrevista e de questionário, auscultaram-se académicos afiliados a três escolas superiores de educação da região de Lisboa e Vale do Tejo. Os resultados revelam uma tendência para processos de aprendizagem de cariz artesanal, sendo valorizado o autoestudo e a socialização. No entanto, verifica-se um reconhecimento da relevância da formação pedagógica, em especial para quem não detém formação qualificante para outros níveis de ensino, surgindo como crença perfilhada a ideia de que as aprendizagens pedagógicas adquiridas para outros contextos de educação e ensino podem ser transferidas para a atuação docente no nível do ensino superior.

\section{PALAVRAS-CHAVE}

pedagogia do ensino superior; desenvolvimento profissional; formação pedagógica; ensino superior.

'Universidade de Lisboa, Lisboa, Portugal. 


\title{
PEDAGOGICAL TRAINING AND PROFESSIONAL DEVELOPMENT IN HIGHER EDUCATION: PROFESSOR PERSPECTIVES
}

\begin{abstract}
The text presents the results of a study that sought to understand which practices are recognized by higher education teachers as promoting learning and professional development, particularly in the teaching component. It also aimed to understand how these actors perceive the pedagogical training for academics. As part of a mixed approach, using the technique of interview and questionnaire, scholars were affiliated with three higher education schools in the region of Lisbon and Tagus Valley. The results reveal a tendency towards learning processes of artisanal nature, being valued the self-study and the socialization. However, there is a recognition of the relevance of pedagogical training, especially for those who do not have qualifying training for other levels of education, emerging as a belief that the pedagogical learning acquired in other contexts of education and teaching can be transferred for teaching performance at higher education level.
\end{abstract}

\section{KEYWORDS}

higher education pedagogy; professional development; pedagogical training; higher education.

\section{FORMACIÓN PEDAGÓGICA Y DESARROLLO PROFESIONAL EN LA ENSEÑANZA SUPERIOR: PERSPECTIVAS DE DOCENTES}

\section{RESUMEN}

El texto presenta los resultados de un estudio que buscaba darse cuenta de que las prácticas de desarrollo profesional son reconocidas por los maestros de educación superior, en particular para la dimensión de enseñanza. También pretendía comprender cómo estos actores perciben la formación pedagógica. Como parte de un enfoque mixto, utilizando la técnica de entrevista y cuestionario, los académicos se afiliaron a tres escuelas de educación superior en la región de Lisboa y el valle del Tajo. Los resultados revelan una tendencia hacia procesos de aprendizaje de naturaleza artesanal,valorando el autoestudio y la socialización. Sin embargo, hay un reconocimiento de la relevancia de la formación pedagógica, especialmente para aquellos que no tienen formación calificada para otros niveles de educación, surgiendo como una creencia de que el aprendizaje pedagógico adquirido en otros contextos de educación y enseñanza puede ser transferido para el desempeño docente en el nivel de educación superior.

\section{PALABRAS CLAVE}

pedagogía de la enseñanza superior; desarrollo profesional; formación pedagógica; enseñanza superior. 


\section{INTRODUÇÃO}

A docência no ensino superior configura-se como uma área a requerer bastante atenção. Se, por um lado, é de certa forma pouco usual o questionamento sobre o exercício profissional dos docentes desse nível de ensino, mas ao qual se outorga a responsabilidade pela produção e divulgação do saber, por outro lado os desafios que se colocam ao ensino superior instigam à problematização do(s) modo(s) como se ensina e aprende. Mormente, não se pode ignorar o paradoxo de que num contexto em que se constrói conhecimento sobre educação e no qual esse saber é objeto de ensino e requisito de qualificação para o exercício da profissão em todos os outros níveis de escolaridade, concomitantemente não se o reconheça ou considere quando se reporta ao exercício docente em seu próprio seio (Cunha, 2010; Elton, 2009; Leite e Ramos, 2010; Tardif, 2000).

Com efeito, o cenário do ensino superior tem sido palco de uma "naturalização" na docência, dispensando uma qualificação pedagógica especializada legitimadora, depreendendo ou um menosprezo da componente docente perante outras funções que caracterizam a atuação profissional ao nível do ensino superior ou uma convicção generalizada de que, no caso particular do ensino superior, basta saber para saber ensinar, relegando o saber docente para a esfera das capacidades e propensões particulares de cada um (Almeida, 2018).

Pese embora o panorama descrito, é notória a amplificação da preocupação social e institucional com a qualidade do ensino-aprendizagem. Essa crescente inquietação deve-se a diversos fatores:

1. à observação de grandes níveis de insucesso, anteriormente visíveis em outros níveis de ensino, mas que atualmente também estão patentes no ensino superior (Estrela, 2010; Flores e Viana, 2007);

2. à visível insatisfação dos alunos relativamente à prestação pedagógica de muitos dos seus professores, plasmada nos processos de avaliação dos docentes pelos estudantes (Estrela, 2010);

3. a algumas inquietações introduzidas pelo Processo de Bolonha, em que se preconiza nomeadamente a necessidade de generalização do paradigma da aprendizagem por oposição ao paradigma instrucional dominante, pondo em causa conceções de ensino e de aprendizagem enraizadas (Leite, 2010);

4. a que se juntam pressões de organizações internacionais, por exemplo da Organização para a Cooperação e Desenvolvimento Econômico (OCDE) (Guellec et al., 2018), que em seu mais recente relatório recomenda o incentivo à formação pedagógica dos académicos.

Afigura-se-nos também como um reflexo da crescente atenção que os processos de formação pedagógica e de desenvolvimento profissional têm recebido no ensino superior, a criação de unidades ou departamentos, especialmente vocacionadas para esse fim. Entre outras atividades, essas unidades têm a seu cargo a deteção de necessidades e a organização de planos de formação, alargando a sua atividade, em alguns casos, à investigação educacional. Na Europa, é no Reino Unido que encontramos uma maior tradição a esse nível. Os cursos de formação inicial, em 
particular, são já uma prática comum no Reino Unido (Elton, 2009; Gibbs, 2004), assistindo-se a um incremento dos programas de formação contínua. Fora da $\mathrm{Eu}-$ ropa, é na Austrália, Estados Unidos e Canadá que nos deparamos com um grande número de iniciativas nesse âmbito (Almeida, 2018).

Em Portugal, a referência a mecanismos ou projetos de promoção de desenvolvimento profissional associados a práticas formativas surge ainda de forma pontual, ${ }^{1}$ não existindo uma cultura de formação e de apoio ao desenvolvimento profissional para o exercício docente.

Tendo argumentado sobre a premência de problematizar o modo como os professores do ensino superior exercem a atividade docente, é nossa intenção dar conta neste texto de um recorte de um estudo mais alargado em que se procurou compreender o processo de desenvolvimento profissional dos docentes do ensino superior, circunscrevendo-nos agora às perceções que docentes de escolas superiores de educação da região Portugal de Lisboa e Vale do Tejo têm sobre práticas indutoras de desenvolvimento profissional e, em particular, sobre papel da formação pedagógica.

Trata-se de um estudo que recorre a uma abordagem mista, tendo como técnicas de recolha de dados a entrevista e o questionário.

Nos pontos seguintes daremos conta de algumas ancoragens teóricas, nomeadamente da reflexão em torno das possibilidades de transição de um paradigma artesanal para uma lógica de aprendizagem profissional no âmbito da pedagogia do ensino superior, bem como sobre as práticas que poderão contribuir para o desenvolvimento profissional dos professores, discutindo, de forma mais atenta, o lugar que a formação pedagógica especializada poderá ocupar. Seguem-se uma secção dedicada à metodologia, outra à apresentação e discussão dos resultados e, por fim, tecemos algumas considerações finais.

\section{DO PARADIGMA ARTESANAL À FORMAÇÃO PEDAGÓGICA DOS DOCENTES DO ENSINO SUPERIOR}

Como sublinhámos na introdução deste texto, o reconhecimento da necessidade de preparação pedagógica dos professores do ensino superior é hoje um imperativo de ordem social e profissional. Com efeito, admite-se que a profissão docente no ensino superior requer uma formação especializada sustentadora da prática docente, contrariando o tradicional empiricismo despojado de teoria que marca a atuação docente, como procurámos discutir de seguida.

Ao problematizar a docência no ensino superior, enquanto prática desprovida de uma preparação especializada e deliberada, torna-se inevitável equacionar os modos como os professores desse nível de ensino aprendem e se desenvolvem profissionalmente.

Desde logo, assumimos que o desígnio do desenvolvimento profissional será o de possibilitar a realização do papel profissional no sentido de uma melhoria da profissionalidade docente (Cruz, 2006; Day, 2001; Marcelo, 2009), papel este vinculado a um ideal de profissão socio-historicamente situado.

1 Veja-se, por exemplo, as experiências relatadas por Alarcão e Gil (2004), Flores (2007) e Leite e Ramos (2010). 
Se a noção de profissionalismo docente espelha "o que significa ser professor" (Flores e Viana,2007), remetendo para a construção de uma identidade profissional, a que se aliam os aspetos éticos e deontológicos da profissão (Estrela, 2010), já a conceção de profissionalidade incorpora uma vertente de natureza teórico-prática, alicerçada em um corpus de conhecimento próprio, sustentador da ação e de uma reflexão sobre a prática informada pela teoria (Leite e Ramos, 2010; Roldão, 2009).

O pressuposto plasmado na afirmação anterior remete-nos, então, para a ideia de que o domínio dos conhecimentos (especializados), bem como a capacidade para a sua atualização, são traços determinantes da profissionalidade docente, operando, concomitantemente, como fonte de legitimação profissional (Shulman, 2004; Tardif, 2000).

A situação da legitimação profissional no ensino superior é em Portugal, assim como em outros países, de natureza fragmentada. Se, por um lado, a elevada qualificação na área disciplinar e a preparação para a atividade investigativa são características marcantes desse grupo profissional, já o conhecimento de natureza pedagógica é diminuto como condição de entrada na profissão, sendo, quanto muito, reduzido à condição de "experiência acumulada". A esse propósito, erguem-se diversas vozes críticas, como é o caso de Cunha (2010, p. 70) que refere:

contrariando a lógica de legitimação dos títulos profissionais, dos quais a universidade é guardiã, são eles "práticos" portadores de saberes provenientes do senso comum, desprovidos de teoria e reflexão sistemática. Exercem, como diz Arroyo, "uma profissão sem ofício e um ofício sem profissão".

Para além da ausência de mecanismos de preparação à entrada na profissão, sublinhámos ainda a natureza esporádica e episódica de experiências e dispositivos de apoio ao desenvolvimento profissional ao longo da carreira (Cruz Tomé, 2003; Cunha, 2010; Zabalza, 2004). Somam-se aos argumentos esgrimidos até aqui, os reptos lançados por organismos supranacionais, como é o caso da Comissão Europeia, os quais advogam a evolução de um paradigma instrucional ainda dominante nas instituições académicas para um paradigma da aprendizagem, sustentador de uma orientação pedagógica centrada no aluno e na aprendizagem, por conseguinte afetando modos de ser, saber e agir enquanto docente.

\section{PRÁTICAS PROMOTORAS DE DESENVOLVIMENTO PROFISSIONAL E O CONTRIBUTO DA FORMAÇÃO PEDAGÓGICA}

Debruçar-nos-emos agora sobre a questão das práticas indutoras de desenvolvimento profissional docente, na qual incluímos a formação enquanto oportunidade de aprendizagem e desenvolvimento profissional, por oposição a uma conceção atomista de formação. Nessa perspetiva, a formação surge integrada em processos que valorizam concomitantemente o desenvolvimento individual e o desenvolvimento da organização.

$\mathrm{Na}$ literatura é já manifesto o reconhecimento de efeitos positivos decorrentes do envolvimento dos professores em iniciativas de formação pedagógica, 
nomeadamente pelo contributo dessas iniciativas na aproximação dos docentes a perfis de orientação pedagógica mais centrados na aprendizagem. Veja-se, a esse propósito, os estudos de Stes e Van Petegem (2014) que identificam conceções mais orientadas para os estudantes e sua aprendizagem em docentes que participaram em programas de formação pedagógica comparativamente a docentes que não participaram. Essas mudanças, operadas no nível das conceções e orientação pedagógica dos professores, são também reportadas por Gibbs (2004) ao estudar o impacto dos programas de formação desenvolvidos no Reino Unido.

Por seu turno, o trabalho de Darling-Hamond et al. (2009) tem a particularidade de revelar os efeitos nos estudantes decorrentes do envolvimento sistemático e prolongado dos professores em modalidades de formação pedagógica. Com efeito, são assinalados resultados no nível da melhoria da qualidade das aprendizagens dos alunos, contrariamente ao que acontece quando a formação é episódica e de curta duração.

Diante dos argumentos que vimos debatendo, a formação pedagógica é, indubitavelmente, o caminho a seguir para prover os académicos com os saberes necessários para uma práxis efetiva, no sentido em que a dinamização dos processos de ensino-aprendizagem deverá dar-se de forma consciente e alicerçada em referenciais teóricos (Leite e Ramos, 2010; Zabalza, 2004, 2007), mais consentâneos com uma orientação pedagógica menos centrada no professor e em práticas transmissivas e mais focada no aluno e na aprendizagem (Gibbs, 2004; Trigwell et al., 2008).

Não obstante o inegável mérito que na literatura, se reconhece à formação pedagógica (depreenda-se que não necessariamente refém de modelos escolarizados), esta não está ainda plenamente enraizada em uma cultura de desenvolvimento profissional dos académicos. Com efeito, estudos como o de Knight, Tait e Yorke (2006) ou o de Pill (2006) apontam para o predomínio do recurso a fontes de aprendizagens não formais, decorrente, entre outras, do reportório de experiências docentes constituído, experiências ora vividas na primeira pessoa, ora observadas em terceiros enquanto alunos, e na partilha e trabalho conjunto com os pares.

O predomínio de um paradigma artesanal entre os professores, atestado pelos estudos anteriormente referidos, aliado, como vimos, à inexistência de requisitos de formação pedagógica no acesso à profissão, acaba por, inevitavelmente, conduzir a uma sobrevalorização da prática (Cunha, 2010; Zabalza, 2007). No entanto, a acumulação de experiência per se pode ser limitadora, impondo limites ao questionamento sobre esse processo e circunscrevendo a prática do professor a uma atuação rotineira e à mimetização dos modelos observados (Cruz,2006; Day,2001,2007; Feixas, 2004; Leite e Ramos, 2010; Zabalza, 2007, entre outros). Ademais, esse tipo de aprendizagem tem a desvantagem acrescida de não permitir aceder aos princípios e quadros teóricos que fundamentam tais práticas, proporcionando tão somente o acesso a um conhecimento superficial, assistemático e vago, que acaba por ser determinado mais por intuições ou crenças pessoais do que por princípios teóricos consistentes (Zabalza, 2007).

Debruçando-se sobre os processos de aproximação ao conhecimento sobre a docência no ensino superior, Zabalza (2007) identifica duas outras vias, para além da aproximação de cariz empirista e artesanal, a saber: a aproximação profissional e a aproximação técnica e especializada. A primeira refere-se a uma abordagem sistemática e fundamentada na teoria e na investigação, de natureza profissiona- 
lizante, e a segunda, própria de especialistas e investigadores sobre o ensino, serve de dispositivo para identificar e descrever de forma sofisticada os diversos fatores e condições implicados nos processos de ensino-aprendizagem.

Autores como De Ketele (2003) e Cruz (2006) identificam diferentes práticas promotoras de aprendizagem e desenvolvimento profissional. De Ketele (2003), para além dos processos de iniciativa pessoal (em que assinala a primazia do informal), refere ainda o potencial regulador dos processos de avaliação do ensino pelos estudantes; as iniciativas pedagógicas inovadoras; os processos de investigação pedagógica; os esquemas de formação organizados; os sistemas de acompanhamento, como é o caso das tutorias e o envolvimento em projetos de colaboração internacionais.

Por seu turno, Cruz (2006) enumera seis modalidades de apoio ao desenvolvimento profissional docente, mencionando o estudo autónomo, apoiado na literatura; processos baseados em itinerários formativos mais formais; a aprendizagem profissional cooperativa; dispositivos apoiados na análise e reflexão sobre as práticas; modalidades centradas em abordagens de melhoria da organização e, por fim, modalidades baseadas na investigação.

As tipologias apresentadas parecem integrar processos e dispositivos que não são mutuamente exclusivos, deixando antes entrever a sua complementaridade e a possibilidade da sua integração em projetos mais ambiciosos de desenvolvimento profissional e de desenvolvimento organizacional. Reconhece-se, assim, o lugar dos processos de desenvolvimento autónomo, em que é o próprio sujeito que decide o que precisa de aprender e assume a responsabilidade pelo seu próprio trajeto, designado por Marcelo (2009) por aprendizagem independente, complementados pelo envolvimento dos docentes em projetos $n a$ e $d a$ própria instituição.

\section{METODOLOGIA}

O estudo realizado teve como propósito contribuir para a compreensão do processo do desenvolvimento profissional dos professores na vertente docente da sua profissão. No recorte que apresentamos, damos particular atenção às perceções dos docentes do ensino superior relativas aos acontecimentos e circunstâncias que consideram ter desempenhado um papel em seu processo de aprendizagem e desenvolvimento profissional, perscrutando aqui em particular o papel que a formação pedagógica assumiu ou que potencialmente poderá vir a assumir.

A tentativa de integração da investigação em uma matriz paradigmática resulta num exercício inexequível atendendo aos opostos e inconciliáveis pressupostos ontológicos e epistemológicos que opõem os paradigmas positivista/naturalista e fenomenológico/hermenêutico, pelo que optamos por contextualizar o estudo com base na abordagem seguida, como propõe Shulman (1986). Nesse sentido, situamos o estudo no quadro de uma abordagem mista, integrando duas etapas sequenciais e complementares, em que se conjugam métodos qualitativos e quantitativos, adequados à procura de evidências que permitam contribuir para um maior esclarecimento dos objetivos do estudo.

Com vista a uma exploração da temática em estudo, foram entrevistados em profundidade doze docentes do ensino superior de uma escola superior de educação da zona geográfica portuguesa de Lisboa e Vale do Tejo, quando optamos por 
circunscrever o estudo aos docentes afetos aos cursos de formação inicial de professores. A delimitação a esse grupo particular de docentes deve-se a duas ordens de razão. Uma, de ordem mais pragmática, é inerente a condicionalismos temporais e logísticas que não permitem abarcar docentes de todas as áreas do ensino superior. A segunda decorre do caracter extremamente peculiar da atuação dos docentes na formação de professores. Referimo-nos à situação singular em que o ensino é sincronicamente objeto de ensino e de prática e ainda campo de investigação.

As entrevistas realizadas foram de tipo semiestruturado, tendo sido construído um guião orientador para o efeito. Intencionalmente, procurámos que as entrevistas preservassem alguns traços autobiográficos, tendo sido estimulado o relato da história pessoal por meio da narrativa de experiências e episódios, refletidos e reconstruídos pelos sujeitos, experiências estas que são simultaneamente de natureza pessoal e social e que se situam num continuum entre o passado, o presente e o futuro (Clandinin e Connelly, 2000; Freeman, 2007).

Para análise das entrevistas, procedemos uma análise de conteúdo temática predominantemente indutiva (Bardin, 2009), integrando uma análise horizontal (transversalidade temática) do corpus documental e, acompanhada por uma decifração estrutural, centrada em cada entrevista, procurando a complementaridade e o enriquecimento entre os dois processos (Bardin, 2009; Robert e Bouillaguet, 2002).

A unidade de enumeração ou de contagem definida para o estudo foi a entrevista ou o sujeito, delimitando-se a unidade de registo como o segmento de conteúdo com sentido próprio, obedecendo, assim, a um critério de recorte de ordem semântica (D'Unrung apud Bardin, 2009).

Para validação interna do sistema de categorização emergente do processo de análise de conteúdo, recorremos ao acordo entre juízes, solicitando a diversos especialistas a testagem do sistema de categorias mediante sua aplicação ao material em bruto (protocolos das entrevistas).

$\mathrm{Na}$ segunda fase do trabalho, com base na literatura e nos dados provenientes da análise de conteúdo das entrevistas, procedemos a construção, validação e aplicação de um questionário a toda a população docente vinculada à formação inicial de professores do subsistema politécnico público da região de Lisboa e Vale do Tejo. ${ }^{2}$

A adoção da técnica do questionário visou ao alargamento do número de docentes abrangido pelo estudo. Foi utilizada uma escala de resposta de likert de cinco pontos em que se solicita aos inquiridos que se posicionem manifestando seu grau de concordância com as afirmações apresentadas, sendo o valor mais baixo da escala correspondente a discordo totalmente (1), seguindo-se discordo (2), não concordo nem discordo (3), concordo (4) e concordo totalmente (5).

Os dados obtidos por meio do questionário foram sujeitos a procedimentos de análise estatística com recurso ao uso do softwere SPSS. Em um primeiro momento, a análise foi de caracter descritivo e, num segundo momento, recorreumos a procedimentos de análise que visaram à verificação da influência das variáveis

2 Para maior detalhe sobre o processo de construção e validação do instrumento consultar Almeida (2018). 
sociodemográficas dos respondentes no modo como se posicionam nas suas respostas. Nessa segunda fase foram aplicados os testes de Mann-Whitney e de Kruskall-Wallis, em virtude das variáveis em análise.

\section{APRESENTAÇÃO E DISCUSSÃO DOS RESULTADOS}

\section{PARTICIPANTES NO ESTUDO}

As entrevistas abrangeram doze docentes, com idade compreendida entre 35 e 55 anos. $\mathrm{O}$ grupo incluiu maioritariamente docentes do género feminino. Apenas quatro dos entrevistados eram do género masculino. Tendo em vista assegurar uma diversificação de docentes a entrevistar, procuramos incluir titulares de diferentes graus académicos e em áreas distintas, académicos com e sem experiência de ensino anterior e também com um número de anos experiência de ensino no ensino superior variável. Em termos de posicionamento na carreira, o grupo integrou principalmente professores adjuntos, embora contando com dois professores coordenadores e dois assistentes.

Relativamente ao questionário aplicado na segunda fase do estudo, este foi distribuído a todos os 152 docentes das escolas superiores de educação (ESEs) situadas na zona de Lisboa e Vale do Tejo, afetos a diversas disciplinas de cursos de formação inicial de professores. Conseguimos, por meio de dois momentos de aplicação, obter uma taxa de resposta de $55 \%$.

Analisando os dados de caracterização sociodemográfica obtidos, releva-se, sem surpresa, a presença de uma maioria de respondentes do género feminino $(68,7 \%)$, expectável na medida em que a feminização do ensino nessa área de formação é um fenómeno reconhecido em Portugal.

Os dados revelam também que os respondentes proveem de diferentes áreas disciplinares, com anos de experiência docente também variáveis. Em escalões etários, os professores situam-se predominantemente entre 50 e 59 anos e entre 30 e 39 anos (respetivamente 33,7\% e 32,5\%).

A análise da categoria profissional indica-nos que um pouco mais de metade dos docentes são professores adjuntos $(56,6 \%)$, seguindo-se os professores no nível inicial da carreira (professores assistentes) (31,3\%) e, com uma representação menos expressiva, surgem os de categoria profissional mais avançada, os professores coordenadores (12\%).

\section{RESULTADOS DAS ENTREVISTAS}

A análise de conteúdo efetuada permitiu agregar um conjunto de ideias, subdividindo-se em dois subtemas, a saber: "processo de desenvolvimento profissional" e "formação pedagógica preconizada" (Quadro 1).

No primeiro subtema emergem ideias inerentes às práticas indutoras de desenvolvimento profissional adotadas pelos entrevistados ao longo de suas trajetórias profissionais e a identificação de fatores que contribuíram para retardar ou acelerar esse processo. ${ }^{3}$

3 Para maior detalhe, ver Almeida (2018). 
Quadro 1-Subtemas e categorias do tema.

\begin{tabular}{|l|c|}
\hline Subtema & Categorias \\
\hline \multirow{4}{*}{ Processo de desenvolvimento profissional } & Práticas indutoras de desenvolvimento profissional \\
\cline { 2 - 2 } & Fatores inibidores \\
\cline { 2 - 2 } & Fatores potenciadores \\
\hline \multirow{4}{*}{ Formação pedagógica preconizada } & Pertinência \\
\cline { 2 - 2 } & Público-alvo \\
\cline { 2 - 2 } & Temáticas \\
\cline { 2 - 2 } & Modalidades \\
\hline
\end{tabular}

Fonte: Banco de dados da pesquisa.

No segundo subtema os entrevistados focam-se na argumentação relativamente à relevância da formação pedagógica, ao público-alvo preferencial, expressando ainda a sua opinião sobre as modalidades que deverão ser adotadas e dando sugestões para as temáticas a contemplar.

Passemos a uma análise mais detalhada de cada um dos subtemas.

No subtema processo de desenvolvimento profissional, enquadram-se as referências às iniciativas e processos reconhecidos como estando presentes ao longo de sua trajetória profissional, categoria que mais se destaca (Quadro 2).

Quadro 2- Práticas indutoras de desenvolvimento profissional.

\begin{tabular}{|l|c|c|}
\hline Subcategorias & FRC & UE \\
\hline Autoestudo & $14 \%$ & $75 \%$ \\
\hline Formação formal & \multirow{2}{*}{$31,5 \%$} & $100 \%$ \\
\hline - Conferente de grau & & $92 \%$ \\
\cline { 1 - 1 } - Não conferente de grau & \multirow{2}{*}{$2,3 \%$} & $58 \%$ \\
\cline { 1 - 1 } Desafios de carreira & \multirow{2}{*}{$12,3 \%$} & $42 \%$ \\
\hline Experiência & & $75 \%$ \\
\hline Socialização profissional & \multirow{2}{*}{$39,9 \%$} & $92 \%$ \\
\hline Trabalho colaborativo & & $92 \%$ \\
\hline Tutoria & & $50 \%$ \\
\hline Modelação & \multirow{2}{*}{$100 \%$} & $58 \%$ \\
\hline TOTAL & & \\
\hline
\end{tabular}

FRC: frequência relativa diante da categoria; UE: percentagem de unidades de enumeração. Fonte: Banco de dados da pesquisa.

Como se observa no Quadro 2, a formação formal, na forma de cursos conferentes de grau, é consensualmente apontada como fonte de aprendizagem. Não obstante os cursos referidos não abrangerem uma formação no âmbito da pedagogia do ensino superior, não deixam de lhe ser reconhecidos benefício em 
termos de aprendizagem e aprofundamento de saberes e competências necessários ao desempenho profissional. Particularmente, referem o contacto com alguns princípios e pressuposto para sustentação das práticas, mencionando seu contributo na mudança de conceções. Importa também sublinhar que quase metade dos sujeitos admite que após a formação inicial a procura de cursos conferentes de grau se deve essencialmente a exigências do sistema de progressão na carreira. Como afirma um entrevistado:

depois tenho que tentar encontrar um caminho... em parte porque gosto de estudar, mas também porque é importante em termos de carreira. (D5)

Para além da frequência de cursos pós-graduados, os processos de socialização profissional e o autoestudo são também apontados como fontes preferenciais de aprendizagem. O trabalho colaborativo com os colegas é extremamente valorizado, quer decorra de circunstâncias mais formalizadas, quer provenha de situações mais informais, em que há lugar a partilha e a discussão de experiências e materiais. Essa valorização do trabalho com os pares fica também evidenciada no estudo de Morosini et al. (2016). Veja-se, por exemplo, o que diz um dos entrevistados

havia sempre uma socialização profissional na base da partilha muito tácita, muito informal, na partilha de documentos, depois nas aulas que dávamos em conjunto! (D1)

A maioria dos docentes reconhece tal-qualmente a aprendizagem por modelação. Salientam, por exemplo, o caracter marcante da observação daqueles que foram seus professores ao longo do percurso escolar e formativo, processo que conduziu à rejeição ou integração de determinadas práticas em seu próprio reportório, sustentando a perspetiva em que se aponta para o forte impacto que exposição a modelos ou contramodelos tem no profissionalismo e profissionalidade do docente e que, como nos diz Feixas (2010, p. 35, tradução nossa), "permeabiliza e impregna de sensibilidade didática a experiência docente nas universidades".

A título ilustrativo das ideias anteriores, transcrevemos o que diz um dos entrevistados:

no mimetismo que foi fundamental para a minha formação [...] era tudo muito intuitivo, fruto do debate com os meus colegas e fui utilizando as estratégias que achava que eram as mais interessantes... estratégias que eu não tive como aluno do ensino superior. Eu tive estratégias de... a dictorium scriptorium. (D1)

O apoio tutorial é também apontado como tendo contribuído para o desenvolvimento profissional. Referem, a esse propósito, a importância do papel de colegas mais experientes ou dos orientadores em processo de formação avançada.

Em síntese, a análise efetuada até aqui,permite perceber que, para além da formação académica conferente de grau e que não se destina à preparação para o exercício docente no ensino superior, as vias não formais são as mais comuns, corroborando os resultados dos estudos de Knight, Tait e Yorke (2006) e de Pill (2006). 
As ideias expressas pelos entrevistados quanto ao papel da formação pedagógica no ensino superior são espelhadas nas categorias patentes no Quadro 3. São tratados aspetos como a pertinência de uma formação pedagógica, o público-alvo a abranger, sendo ainda apontadas temáticas e modalidades preferenciais.

Quadro 3 - Formação pedagógica preconizada.

\begin{tabular}{|l|c|c|c|}
\hline Categoria & Subcategoria & FRC & UE \\
\hline Relevância & & & $50 \%$ \\
\hline \multirow{4}{*}{ Público-alvo } & Docentes em início de carreira & $6 \%$ & $17 \%$ \\
\cline { 2 - 4 } & Docentes sem experiência de ensino & $\mathbf{4 6 , 3 \%}$ & $\mathbf{6 7 \%}$ \\
\cline { 2 - 4 } & Professores em geral & $13,4 \%$ & $33 \%$ \\
\hline \multirow{3}{*}{ Temáticas } & Currículo & $\mathbf{5 4 , 8 \%}$ & $\mathbf{5 8 \%}$ \\
\cline { 2 - 4 } & Formação de adultos & $25,8 \%$ & $17 \%$ \\
\cline { 2 - 4 } & Formação de professores & $6,5 \%$ & $8 \%$ \\
\cline { 2 - 4 } & Processo de Bolonha e as mudanças preconizadas & $12,9 \%$ & $8 \%$ \\
\hline \multirow{3}{*}{ Modalidades } & Investigação/Reflexão sobre a prática & $\mathbf{4 5 , 3 \%}$ & $\mathbf{7 5 \%}$ \\
\cline { 2 - 4 } & Seminário & $20,6 \%$ & $33 \%$ \\
\cline { 2 - 4 } & Ciclo de estudos & $7,5 \%$ & $17 \%$ \\
\cline { 2 - 4 } & Sistema tutorial & $26,4 \%$ & $25 \%$ \\
\hline
\end{tabular}

FRC: frequência relativa diante da categoria.

Fonte: Banco de dados da pesquisa.

É de assinalar o facto de metade dos entrevistados se manifestarem favoravelmente quanto à importância de uma formação pedagógica especificamente dirigida aos docentes do ensino superior, considerando que essas iniciativas se deverão destinar a todos os docentes, embora alguns entrevistados sejam de opinião que esta se deverá destinar preferencialmente a docentes sem experiência de ensino anterior. Parece, pois, denotar-se implicitamente nessa posição uma convicção de que o conhecimento pedagógico adquirido para outros contextos é transferível para o ensino superior. Essa posição não será especialmente sensível a uma pedagogia do ensino superior, sendo, no contexto específico de atuação desses docentes, fechada às correntes que defendem a especificidade de uma pedagogia da formação de professores (Loughran, 2006, 2007). Vejamos o que, a esse propósito, é afirmado por um dos entrevistados:

Temos andado a usar como formação pedagógica a formação pedagógica que os professores já tinham antes de ser formadores! A partir do momento em que os professores do ensino superior e educação deixem de ser recrutados de entre os professores do ensino básico e secundário isso acaba! $\mathrm{E}$ a coisa... eu penso que se vai tornar muito mais complicado se não houver uma formação específica para eles. (D2) 
Outros entrevistados referem,

a formação... acho que quem nunca foi professor tem que ter umas luzes... do que...da parte científica do que é ser professor... como não sei, mas acho que se não tivesse sido professora antes era impensável, estaria completamente às escuras. (D8)

De qualquer forma eu acho que ajuda, para quem inicia, não ser lançado às feras, não é?! Porque eu lembro-me da minha primeira sessão, eu tinha 24 anos! [...] Foi a minha prova de fogo! (D1)

As modalidades de formação mais apreciadas pelos entrevistados são as que proporcionam a implicação em processos de investigação e de reflexão sobre as práticas. Outras modalidades referidas, embora que de forma pouco expressiva, são os formatos de seminário, o apoio tutorial e, de forma muito residual, os ciclos de estudos.

As temáticas a merecer maior destaque são as de âmbito curricular e didático. Destacam-se as questões relacionadas com a organização do processo de ensino-aprendizagem e as metodologias de ensino e, em particular, a avaliação das aprendizagens que é apontada como área deficitária, esta última corroborando o que nos diz a literatura sobre as insuficiências dos docentes no campo da avaliação (Zabalza, 2007). Afirma-se, por exemplo, que seria de abordar o desenvolvimento curricular, aqui especificamente das realidades do pré-escolar, $1^{\circ}$ ciclo etc... e sobre avaliação, pois cometem-se vários erros. (D8)

Como diz um docente,

logo no primeiro ano fiz um erro de palmatória do ponto de vista da avaliação, aprendi nesse ano para o próximo, e para o seguinte, e pronto. É assim. (D1)

A especificidade da formação de adultos, a formação de professores e as mudanças preconizadas pelo designado Processo de Bolonha, nomeadamente as implicações da preconizada adoção generalizada do paradigma da aprendizagem, são outros temas sugeridos.

\section{RESULTADOS DO QUESTIONÁRIO}

Os resultados provenientes da aplicação do questionário são apresentados de forma a evidenciar os aspetos que mais se destacam relativamente à apreciação dos contributos da formação para a aprendizagem e desenvolvimento profissional. Assim, na Tabela 1 reunimos os itens que acolheram uma apreciação muito positiva por mais de três quartos do grupo de respondentes.

Verifica-se que, tal como ocorrera nas entrevistas, as modalidades formativas preferenciais são as que potenciam processos de investigação e reflexão sobre as práticas $(92,8 \%)$. Associado a essa preferência surge o interesse de que a formação seja desenvolvida no seio da instituição a que se encontram filiados, ajustando-se aos interesses e necessidades dos docentes, ora mais centrados nas áreas disciplinares, ora dirigida a 
Tabela 1 - A formação poderá contribuir para melhorar o meu desempenho como docente se... (mais de 75\% de acordo)

\begin{tabular}{|c|c|c|c|c|c|c|}
\hline & $\begin{array}{l}\text { Discordo } \\
\text { Totalmente }\end{array}$ & Discordo & $\begin{array}{c}\text { Não } \\
\text { concordo } \\
\text { nem } \\
\text { Discordo }\end{array}$ & Concordo & $\begin{array}{l}\text { Concordo } \\
\text { Totalmente }\end{array}$ & $\mathrm{C}+\mathrm{CT}$ \\
\hline $\begin{array}{l}\text { 7. incidir na } \\
\text { investigação e } \\
\text { reflexão sobre as } \\
\text { nossas práticas }\end{array}$ & & & 7,2 & 39,8 & 53,0 & 92,8 \\
\hline $\begin{array}{l}\text { 6. incidir sobre a } \\
\text { área científica das } \\
\text { disciplinas que leciono }\end{array}$ & 1,2 & 3,6 & 7,2 & 51,8 & 36,1 & 87,9 \\
\hline $\begin{array}{l}\text { 4. for desenvolvida } \\
\text { no seio da instituição } \\
\text { onde ensino, com a } \\
\text { criação de grupos de } \\
\text { trabalho da minha } \\
\text { área científica }\end{array}$ & & 2,4 & 14,5 & 55,4 & 27,7 & 83,1 \\
\hline $\begin{array}{l}\text { 11. for através } \\
\text { da participação } \\
\text { em encontros de } \\
\text { natureza científica } \\
\text { (seminários, } \\
\text { congressos, etc.) }\end{array}$ & & 2,4 & 14,6 & 48,8 & 34,1 & 82,9 \\
\hline $\begin{array}{l}\text { 1. for desenvolvida } \\
\text { no seio da instituição } \\
\text { onde ensino, } \\
\text { com a criação de } \\
\text { grupos de trabalho } \\
\text { interdisciplinares }\end{array}$ & & 4,8 & 15,7 & 51,8 & 27,7 & 79,5 \\
\hline $\begin{array}{l}\text { 3. for proporcionada } \\
\text { pela instituição onde } \\
\text { leciono, de acordo } \\
\text { com um levantamento } \\
\text { de necessidades e } \\
\text { interesses dos docentes }\end{array}$ & 1,2 & 6,0 & 15,7 & 42,2 & 34,9 & 77,1 \\
\hline $\begin{array}{l}\text { 2. incidir sobre o } \\
\text { sistema educativo e } \\
\text { futuros contextos de } \\
\text { atuação dos alunos }\end{array}$ & 3,7 & 2,4 & 18,3 & 58,5 & 17,1 & 75,6 \\
\hline
\end{tabular}

C+ CT: somatório das respostas nas posições concordo e concordo totalmente.

Fonte: Banco de dados da pesquisa.

grupos interdisciplinares. Como se percebe, a formação pedagógica contextualizada e com foco nas práticas é fortemente valorizada, não obstante também ser distinguida por uma grande maioria a necessidade de formação na área científica lecionada, esta última podendo já ser organizada em instituições especializadas. Veja-se a Tabela 2. 
Tabela 2 - A formação poderá contribuir para melhorar o meu desempenho como docente se... (mais de 50\% de acordo)

\begin{tabular}{|c|c|c|c|c|c|c|}
\hline & $\begin{array}{l}\text { Discordo } \\
\text { Totalmente }\end{array}$ & Discordo & $\begin{array}{c}\text { Não } \\
\text { concordo } \\
\text { nem } \\
\text { Discordo }\end{array}$ & Concordo & $\begin{array}{l}\text { Concordo } \\
\text { Totalmente }\end{array}$ & $\mathrm{C}+\mathrm{CT}$ \\
\hline $\begin{array}{l}\text { 8. for } \\
\text { proporcionada } \\
\text { em cursos } \\
\text { estruturados } \\
\text { e organizados } \\
\text { por instituições } \\
\text { especializadas na } \\
\text { área em que me } \\
\text { interessa obter }\end{array}$ & 2,4 & 6,0 & 19,3 & 45,8 & 26,5 & 72,3 \\
\hline $\begin{array}{l}\text { 13. incidir sobre } \\
\text { a especificidade } \\
\text { do ensino no } \\
\text { ensino superior }\end{array}$ & 4,9 & 11,0 & 18,3 & 51,2 & 14,6 & 65,8 \\
\hline $\begin{array}{l}\text { 9. incidir sobre } \\
\text { modelos de } \\
\text { formação de } \\
\text { professores }\end{array}$ & 3,6 & 4,8 & 30,1 & 44,6 & 16,9 & 61,5 \\
\hline $\begin{array}{l}\text { 14. Se incidir } \\
\text { sobre questões } \\
\text { do currículo } \\
\text { (planificação, } \\
\text { avaliação, etc.) }\end{array}$ & 2,4 & 3,6 & 33,7 & 48,2 & 12,0 & 60 \\
\hline $\begin{array}{l}\text { 10. for orientada } \\
\text { por colegas mais } \\
\text { experientes } \\
\text { (sistema tutorial) }\end{array}$ & 3,6 & 9,6 & 31,3 & 45,8 & 9,6 & 55,4 \\
\hline $\begin{array}{l}\text { 5. incidir sobre } \\
\text { metodologias } \\
\text { de investigação }\end{array}$ & 1,2 & 9,8 & 36,6 & 34,1 & 18,3 & 52,4 \\
\hline
\end{tabular}

$\mathrm{C}+\mathrm{CT}$ : somatório das respostas nas posições concordo e concordo totalmente. Fonte: Banco de dados da pesquisa.

A maioria dos inquiridos parece valorizar as áreas de formação já referidas pelos entrevistados, a que se somam outras. Como se vê na Tabela 2, são preferencialmente apontados temas como a pedagogia do ensino superior; modelos de formação de professores (área em que atuam); sobre questões inerentes à gestão curricular, a que acresce o interesse pelas metodologias de investigação.

São também admitidas as vantagens de um sistema tutorial, tal como também já revelado pelas entrevistas, sendo atribuído a docentes mais experientes esse papel.

Avançamos na análise dos resultados procurando detetar relações entre as opiniões emitidas e as características sociodemográficas dos inquiridos. Recorrendo a 
testes de Mann-Whitney, procurámos verificar a existência de opiniões significativamente diferentes entre sujeitos de diferentes áreas científicas de base e em virtude de terem participado ou não de processos de formação pedagógica (Tabela 3).

Tabela 3 - Testes Mann-Whitney.

\begin{tabular}{l|c|c|c|c|c}
\hline & Item & $\begin{array}{c}\text { Mann- } \\
\text { Whitney U }\end{array}$ & $\begin{array}{c}\text { Wilcoxon } \\
\text { W }\end{array}$ & Z & Sig. $^{*}$ \\
\hline \multirow{2}{*}{$\begin{array}{l}\text { Área científica } \\
\text { de base }\end{array}$} & 11 & 458,500 & 1889,500 & $-2,635$ & 0,008 \\
\cline { 2 - 6 } & 13 & 475,000 & 800,000 & $-2,288$ & 0,022 \\
\cline { 2 - 6 } & 15 & 499,500 & 850,500 & $-2,190$ & 0,029 \\
\hline $\begin{array}{l}\text { Formação } \\
\text { pedagógica }\end{array}$ & 12 & 272,500 & 2618,500 & $-2,753$ & 0,006 \\
\cline { 2 - 6 } & 13 & 292,500 & 2570,500 & $-2,378$ & 0,017 \\
\hline
\end{tabular}

* $\mathrm{p} \leq 0,05$.

Fonte: Banco de dados da pesquisa.

A filiação a áreas científicas distintas é responsável por alguma variação nas respostas. Os resultados mostram que os docentes com formação em Ciências Exatas se destacam perante os outros, manifestando-se mais de acordo com a ideia de que a formação poderá contribuir para melhorar o meu desempenho como docente se for através da participação em encontros de natureza científica (seminários, congressos, etc.) (item 11).

Por seu turno, os professores oriundos de áreas das Humanidades e Ciências Sociais suplantam os restantes considerando que a formação poderá contribuir para melhorar o meu desempenho como docente se incidir sobre a especificidade do ensino no ensino superior (item 13) e que a formação poderá contribuir para melhorar o meu desempenho como docente se for programada e definida pela instituição, como um procedimento regular para todos os docentes (item 15 ).

Cruzando as evidências anteriores, poderemos apontar para uma tendência por parte dos professores das áreas das Ciências Exatas em valorizar encontros científicos mais formais fora da instituição, enquanto os das Humanidades e Ciências Sociais parecem tender mais do que os anteriores para um tipo de formação programada pela instituição e mais focada na formação sobre pedagogia do ensino superior.

Já o facto de terem ou não formação pedagógica distingue os inquiridos quando se posicionam relativamente à afirmação de que a formação poderá contribuir para melhorar o meu desempen ho como docente se incidir sobre psicologia do adolescente e do adulto, nomeadamente processos de desenvolvimento e aprendizagem (item 12) e no que concerne à ideia de que formação poderá contribuir para melhorar o meu desempenho como docente se incidir sobre a especificidade do ensino no ensino superior (item 13). São os professores sem qualquer formação pedagógica os que mais se revêm nas afirmações.

Se a primeira diferença assinalada entre aqueles que têm formação pedagógica e os que não tiveram acesso a essa preparação para o ensino não nos surpreende, uma vez que as questões da psicologia do desenvolvimento e da aprendizagem terão sido abordadas nos processos de formação pedagógica frequentados pelos primeiros, esperávamos 
que a especificidade do ensino superior fosse relevante para ambos, sendo igualmente reconhecida a mais-valia de uma formação específica para esse nível de ensino.

Para as variáveis categoria profissional e anos de experiência no ensino superior, recorremos aos testes de Kruskall-Wallis, cujos resultados estão sintetizados na Tabela 4.

Tabela 4-Testes de Kruskal-Wallis.

\begin{tabular}{l|c|c|c|c}
\hline \multirow{2}{*}{\begin{tabular}{l} 
Variável \\
\multirow{3}{*}{$\begin{array}{l}\text { Categoria } \\
\text { profissional }\end{array}$}
\end{tabular}} & $\begin{array}{c}\text { Chi-square } \\
\left(\chi^{2}\right)\end{array}$ & $\mathrm{Gl}_{(\mathrm{KW})}$ & Sig. $^{*}(\mathrm{p})$ \\
\cline { 2 - 5 } & 3 & 8,683 & 2 & 0,013 \\
\hline \multirow{2}{*}{$\begin{array}{l}\text { Anos de } \\
\text { experiência no } \\
\text { ensino superior }\end{array}$} & 9 & 6,409 & 2 & 0,041 \\
\cline { 2 - 5 } & 6 & 8,395 & 2 & 0,015 \\
\hline
\end{tabular}

* $\mathrm{p} \leq 0,05$.

Fonte: Banco de dados da pesquisa.

Em primeiro lugar, é de salientar que a idade não parece interferir na tendência de resposta nas diferentes faixas etárias. Já a categoria profissional influencia a forma como os docentes se posicionam relativamente a diversas afirmações (Tabela 4). Senão vejamos: os professores adjuntos distinguem-se dos professores de categoria profissional superior (professores coordenadores), exprimindo os primeiros um maior reconhecimento de que a formação poderá contribuir para melhorar o meu desempenho como docente se for proporcionada pela instituição onde leciono, de acordo com um levantamento de necessidades e interesses dos docentes (item 3), bem como concordando com maior veemência com as ideias de que a formação poderá contribuir para melhorar o meu desempenho como docente se for proporcionada em cursos estruturados e organizados por instituiçôes especializadas na área em que me interessa obter formação e de que a formação poderá contribuir para melhorar o meu desempenho como docente se incidir sobre modelos de formação de professores (item 9).

Diante do exposto, poderemos inferir uma maior predisposição dos professores adjuntos para fazer formação do que os seus pares em fases mais avançadas da carreira.

Quanto à influência dos anos de experiência no ensino superior, verificámos que as diferenças significativas se encontram entre o grupo com 11 a 15 anos de experiência relativamente e o grupo de docentes mais experientes (mais de 21 anos), em que os primeiros estão mais de acordo com a ideia de que a formação poderá contribuir para melhorar o meu desempenho como docente se incidir sobre a área cientifica das disciplinas que leciono (item 6).

Os docentes com experiência situada entre os 11 e 15 anos também se distinguem perante os professores mais inexperientes (até 5 anos) na consideração de que a formação poderá contribuir para melhorar o meu desempenho como docente se incidir na investigação e reflexão sobre as nossas práticas (item 7). 
Para além das distinções salientadas, foram também encontradas disparidades entre professores com 6 a 10 anos de experiência e os professores mais experientes (mais de 21 anos). Aqui, os professores com mais anos de ensino revêem-se mais na ideia de que a formação poderá contribuir para melhorar o meu desempen ho como docente se incidir sobre modelos de formação de professores (item 9), denotando possivelmente uma necessidade de atualização da temática que constitui afinal o cerne da área de formação em que lecionam.

\section{CONSIDERAÇÕES FINAIS}

A análise dos resultados obtidos nas duas fases do estudo, conjugando-se com a revisão de literatura, permite-nos destacar algumas tendências, contribuindo para alguns avanços diante das questões apresentadas.

Em primeiro lugar, é encorajador o facto da importância de uma formação pedagógica ser reconhecida pelos docentes, pese, embora, nem sempre seja manifesta a necessidade de uma formação especializada em pedagogia do ensino superior. Com efeito, os participantes no estudo reconhecem mais-valias na criação de dispositivos de formação pedagógica, sobretudo para quem não tem qualquer experiência de ensino anterior, parecendo não ser tão evidente essa necessidade de formação para quem foi preparado para exercer em outros níveis de ensino. Esses dados são denunciadores da prevalência de uma conviç̧ão entre os docentes de que os conhecimentos e as competências adquiridos na formação qualificante para outros níveis de ensino são transferíveis e, aparentemente, o quanto bastam para atuar no ensino superior. No entanto, não se podem descurar as implicações inerentes à passagem da escola para uma carreira académica. Com efeito, essa mudança acarreta desafios e exigências imprevisíveis, decorrentes do trabalho com novos públicos, da inerente e desejável articulação entre ensino e investigação, entre outros. Em geral, mesmo nos casos em que há uma experiência de ensino em outros níveis de escolaridade, a transição entre professor na escola e docente na academia ocorre, na maior parte dos casos, de forma abrupta, sem grande orientação e apoio (Loughran, 2009; Lunenberg e Willemse, 2006), argumento que se presta a favorecer a defesa de mecanismos de apoio à aprendizagem e desenvolvimento profissional adequados ao novo contexto de atuação.

$\mathrm{Na}$ senda dessa última linha de argumentação, enfatizamos os testemunhos recolhidos que, em vez dos anteriores, indiciam um particular interesse e motivação para integrar processos de formação formais no âmbito da pedagogia do ensino superior. Não podemos deixar de interpretar essa manifestação de interesse como um sinal de uma crescente sensibilização do corpo docente para a temática, tal como afirmam Knight, Tait e Yorke (2006).

Acresce ainda, no grupo particular de docentes abrangidos pelo estudo, a sinalização de uma especial disposição para formação gizada em torno das abordagens e modelos de formação de professores. A propensão manifestada para essa área poderá advir não só do interesse em atualizar os quadros teórico-conceptuais de referência que são objeto de ensino, como poderá também refletir uma necessidade de desenvolver competências no quadro de um domínio particular da pedagogia do ensino superior que vem sendo designado e delimitado enquanto pedagogia da formação de professores (Loughran, 2006, 2007, 2009; Lunenberg e Willemse, 2006). 
Evidentemente, não ignoramos a necessidade de formação permanente na área disciplinar de especialização, cientes de que os professores que revelam um maior nível de apropriação e compreensão dos conhecimentos da área disciplinar são também aqueles que têm uma orientação pedagógica mais centrada no aluno, como aliás sustentam os trabalhos de Trigwell et al. (2008). Contudo, partimos do pressuposto de que a formação na área científica é uma vertente que os professores tendem a procurar voluntariamente ou por ditames da carreira, contrariamente ao que acontece com a preparação para o ensino. Com efeito, para a formação científica nas áreas disciplinares, as instituições dispõem tradicionalmente de oferta diversificada, estruturada e sistematizada, sendo também habituais e inúmeros os encontros e fóruns de discussão às escalas nacional e internacional, a que se somam as oportunidades inerentes à participação em projetos de investigação.

O estudo permitiu ainda identificar diversas fontes de aprendizagem a que os docentes recorrem. São adotadas estratégias de autoestudo e é destacado o papel de mecanismos de socialização profissional e aprendizagem entre pares, o que nos leva a considerar que os docentes se sentem impelidos a dar continuidade aos seus processos de aprendizagem. Mormente, esses dados também nos revelam que os projetos de desenvolvimento profissional têm ficado dependentes da diligência e responsabilidade individual, sendo notório o seu carater predominantemente informal e assistemático, como afirmam Zabalza (2004), Knight, Tait e Yorke (2006) e Pill (2006).

Se o valor de uma aprendizagem de cariz informal não é desprezível (De Ketele, 2003; Knight, Tait e Yorke,2006), pode, no entanto, não ser suficiente, uma vez que pode conduzir à manutenção de padrões profissionais rotineiros e obsoletos, decorrentes da incapacidade de alargar quadros de referência potenciadores de um posicionamento problematizador diante das conceções e práticas (Knight, Tait e Yorke, 2006; Zabalza,2004).

É também apreciada uma formação que incida sobre as situações experienciadas, por meio de processos que promovam a indagação e a reflexão sobre o vivido, em linha com as teorias da aprendizagem que sublinham que os processos de aprendizagem em idade adulta deverão ser apoiados pela ligação aos contextos reais para que se tornem significativos (Knowles, 1985).

$\mathrm{Na}$ estimulação ao desenvolvimento profissional dos docentes do ensino superior, a formação, particularmente centrada na componente pedagógica, é encarada pelos participantes no estudo como área a ser estimulada pela própria instituição, corroborando o posicionamento de vários autores que apontam essa área como nevrálgica a desenvolver em nível institucional (Esteves, 2010; Knight, Tait e Yorke, 2006; Zabalza, 2004).

Por tudo o que foi exposto, parece fundamental alargar as práticas de formação e aprendizagem profissional de iniciativa individual a outras iniciativas de cariz coletivo, bem como incrementar o papel das instituições nesse processo.

Destacando o papel das instituições, Esteves (2010, p. 59) refere:

Cremos que não chega reunir umas tantas boas vontades individuais para que se façam inovações pertinentes, consistente e douradoras. Do que se trata é de promover e sustentar processos institucionais de mudança e inovação que contem com a adesão imprescindível dos docentes e que sejam um fator potenciador da mesma. 
Em síntese, consideramos que o estudo sublinha a atualidade e relevância da temática da formação pedagógica no ensino superior e aponta no sentido de que melhorar o processo de ensino-aprendizagem nesse sector passa por investir, de forma intencional, sistemática e coerente, em processos formativos que envolvam os docentes na permanente problematização da prática e na dialética entre teoria e a prática.

A formação pedagógica especializada poderá não só contribuir para operar mudanças no saber e no agir profissional, bem como permitirá reconduzir a vertente docente do trabalho académico a um lugar paritário com as demais componentes que caracterizam a profissão.

Novos estudos, que aprofundem as pistas levantadas e alarguem a auscultação a docentes de outras áreas de ensino, permitirão reforçar tendências e identificar especificidades sobre os modos como os docentes do ensino superior se tornam professores, explorando o tempo e o lugar da formação pedagógica nos processos de desenvolvimento profissional.

\section{REFERÊNCIAS}

ALARCÃO,I.; GIL, V.Teaching and learning in higher education in Portugal: an overview of studies in ICHED. In: GIL, V;; ALARCÃO, I.; HOOGHOFF, H. (eds.). Challenges in teaching \& learning in higher education. Aveiro: Universidade de Aveiro, 2004.p. 195-221. ALMEIDA, M. Desenvolvimento profissional e perfis de orientação pedagógica na docência no ensino superior. Sisyphus Journal of Education, Lisboa, v. 6, n. 3, p. 53-75, 2018. https://doi.org/10.25749/sis.15275

BARDIN, L. Análise de conteúdo. Lisboa: Edições 70, 2009.

CLANDININ, D. J.; CONNELLY, F.M. Narrative inquiry. Experience and story in qualitative research. San Francisco: Jossey-Bass, 2000.

CRUZ TOMÉ, M. A. Necesidade y objectivos de la formación pedagógica del professor universitário. Revista de Educación, España, n. 331, p. 35-66, 2003.

CRUZ,M.F.Desarrollo profesional docente. Granada: Grupo Editorial Universitário, 2006. CUNHA, M. I. Impasses contemporâneos para a pedagogia universitária no Brasil. In: LEITE, C. (ed.). Sentidos da pedagogia no ensino superior. Porto: CIIE, 2010. p. 63-74. DARLING-HAMMOND, L.; WEI, R.; ANDREE, A.; RICHARDSON, N.; ORPHANOS, S. State of the profession. Study measures sattus of professional development. National Staff Development Council, [S.l.], v. 30, n. 2, p. 42-50, 2009. DAY, C. Desenvolvimento profissional de professores: os desafios da aprendizagem permanente. Porto: Porto Editora, 2001.

DAY, C. Pasión por enseñar. La identidad personal e professional del docente y sus valores. 2. ed. Madrid: Narcea, 2007.

DE KETELE,J.M.La formación didáctica y pedagógica de los profesores universitarios: luces y sombras. Revista de Educación, España, n. 331, p. 143-169, 2003.

ELTON, L. Continuing professional development in higher education: the role of the scholarship of teaching and learning. Arts and Humanities in Higher Education, [S.l.], n. 8, p. 247-258, 2009. https://doi.org/10.1177/1474022209339955 
ESTEVES, M. Sentidos da inovação pedagógica no ensino superior. In: LEITE, C. (ed.). Sentidos da pedagogia no ensino superior. Porto: CIIE, 2010. p. 45-62.

ESTRELA, M.T. Ética e pedagogia no ensino superior. In: LEITE, C. (ed.). Sentidos da pedagogia no ensino superior. Porto: CIIE, 2010. p. 11-27.

FEIXAS, M. La influencia de factores personales, institucionales y contextuales en la trayectoria y el desarrollo docente de los profesores universitarios. Educar, Barcelona, n. 33, p. 31-59, 2004. https://doi.org/10.5565/rev/educar.260

FLORES, M. A.; VIANA, I. Profissionalismo docente em transição: as identidades dos professores em tempos de mudança. Braga: Universidade do Minho, 2007.

FREEMAN, M. Autobiographical understanding and narrative inquiry. In: CLANDININ, D. J. (ed.). Handbook of narrative inquiry. Mapping methodology. Thousand: Sage, 2007. p. 120-145.

GIBBS, G. Improving university teaching and learning trough institution-wide strategies. In: GIL, V.; ALARCÃO, I.; HOOGHOFF,H. (orgs.). Challengs in teaching \& learning in higher education. Aveiro: Universidade de Aveiro, 2004. p. 149-166.

GUELLEC, D.; LARRUE, P.; ROY, S.; WEKO, T. OECD. Review of the Tertiary Education. Research and Innovation System in Portugal. Portugal: OECD, 2018.

KNOWLES, M. S. Andragogy in action: applying modern principles of adult learning. San Francisco: Jossey-Bass, 1985.

LEITE, C. Apresentação. In: LEITE, C. (ed.). Sentidos da pedagogia no ensino superior. Porto: CIIE, 2010. p. 7-10.

LEITE, C.; RAMOS, K. Questões da formação pedagógica-didáctica na sua relação com a profissionalidade docente universitária. Alguns pontos para debate. In: LEITE, C. (ed.). Sentidos da pedagogia no ensino superior. Porto: CIIE, 2010. p. 29-45.

LOUGHRAN,J. Developing a pedagogy of teacher education. London: Routledge, 2006. LOUGHRAN, J. Enacting a pedagogy of teacher education. In: LOUGRHAN, J.; RUSSEL, T. (orgs.). Enacting a pedagogy of teacher education. Values, relationships and practices. London: Routledge, 2007.p. 1-15.

LOUGHRAN, J. A construção do conhecimento e o aprender sobre o ensino. In: FLORES, M. A.; VEIGA SIMÃO, A. M. (orgs.). Aprendizagem e desenvolvimento profissional de professores: contextos e perspectivas. Mangualde: Edições Pedago, 2009. p. 17-37.

LUNENBERG, M.; WILLEMSE, M. Research and professional development of teacher educators. European Journal of Teacher Education, United Kingdom, v. 29, n. 1, p. 81-98, 2006. https://doi.org/10.1080/02619760500478621

KNIGHT, P.; TAIT, J.; YORKE, M. The professional learning of teachers in higher education. Studies in Higher Education, United Kingdom, v. 31, n. 3, p. 319-339, 2006. https://doi.org/10.1080/03075070600680786

MARCELO, C. Desenvolvimento profissional docente: passado e futuro. Síshyphus: Revista de Ciências da Educação, Lisboa, n. 8, p. 7-22, 2009.

MOROSINI, M.; FERNANDES, C.; LEITE, D.; FRANCO, M. E.; CUNHA, M. I. A qualidade da educação superior e o complexo exercício de propor indicadores. 
Revista Brasileira de Educação, Rio de Janeiro, v. 21, n. 64, jan./mar. 2016. http:// dx.doi.org/10.1590/S1413-24782016216402

PILL, A. Models of professional development in the education and practice of new teachers in higher education. Teaching in Higher Education, United Kingdom, v. 10, n. 2, p. 175-188, 2006. http://dx.doi.org/10.1080/1356251042000337936

ROBERT, A.; BOUILLAGUET, A. Lanalyse de contenu. 2. ed. Paris: PUF, 2002.

ROLDÃO, M. C. Estratégias de ensino. O saber e o agir do professor. Vila Nova de Gaia: Fundação Manuel Leão, 2009.

SHULMAN, L. Paradigms and research programs in the study of teaching: A contemporary perspective. In: WITTROCK.M. Handbook of research on teaching. New York: McMillan Publishing Company, 1986. p. 3-36.

SHULMAN, L. The wisdom of practice. Essays on teaching, learning, and learning to teach. San Francisco: Jossey- Bass, 2004.

STES, A.; VAN PETEGEM, P. Profiling approaches to teaching in higher education: a cluster-analytic study. Studies in Higher Education, United Kingdom, v. 39, n. 4, p. 644-658, 2014. http://dx.doi.org/10.1080/03075079.2012.729032

TARDIF, M. Saberes profissionais dos professores e conhecimentos universitários. Elementos para uma epistemologia da prática profissional dos professores e suas consequências em relação à formação para o magistério. Revista Brasileira de Educação, Rio de Janeiro, n. 13, p. 5-24, 2000.

TRIGWELL, K.; POSTAREFFA, L.; KATAJAVUORIA, N.; LINDBLOMYLÄNNEA, S. Consonance and dissonance in descriptions of teaching of university teachers. Studies in Higher Education, United Kingdom, v. 33, n. 1, p. 49-61, 2008. https://doi.org/10.1080/03075070701794809

ZABALZA, M. A. La enseñaza universitaria. El escenario e sus protagonistas. 2. ed. Madrid: Narcea, 2004.

ZABALZA, M. A. Competências docentes del profesorado universitario: calidad y desarrollo profesional. Madrid: Narcea, 2007.

\section{SOBRE A AUTORA}

Marta Mateus de Almeida é doutora em educação pela Universidade de Lisboa (Portugal). Professora da mesma instituição.

E-mail:mialmeida@ie.ulisboa.pt

Recebido em 18 de março de 2019 Aprovado em 11 de setembro de 2019 